\title{
Cardiovascular Autonomic Function in Normotensive Men with High Salt and Low Salt Intakes
}

\author{
Win Win Than', Ei Ei Khin², Mya Mya Thwin'3,*
}

\begin{abstract}
Background and Aim: The autonomic nervous system may play an important role in saltinduced increases in blood pressure (BP). The aim of this study is to assess and compare the heart rate $(H R)$ responses to Valsalva maneuver, deep breathing and standing and BP responses to standing and sustained handgrip between normotensive men with habitual high salt intake (HSI) and low salt intake (LSI). Methods: Twenty-fourty years old normotensive men ( $n=34 ; n=17$ for HSI and $n=17$ for LSI) were recruited by collecting 4 early morning spot urine samples. Average estimated $24-\mathrm{hr}$ sodium $\left(\mathrm{Na}^{+}\right)$excretion of 4 urine samples of $\geq 166$ $\mathrm{mmol} /$ day was regarded as $\mathrm{HSI}$ and $<115 \mathrm{mmol} /$ day as LSI. Heart rate responses to Valsalva maneuver, deep breathing and standing (parasympathetic function tests) and BP responses to standing and sustained handgrip (sympathetic function tests) were investigated in both groups. Results: Valsalva ratio (VR) $[1.64 \pm 0.36$ (HSI) vs $1.78 \pm 0.49$ (LSI)], deep breathing difference (DBD) $[24.51 \pm 9.56$ beats/min (HSI) vs $22.93 \pm 6.37$ beats/min (LSI)] and 30:15 ratio [1.34 (1.12-1.46) (HSI) vs 1.19 (1.13-1.52) (LSI)] were not significantly different in both groups. Systolic blood pressure (SBP) change from lying to standing $[-0.67(-4.00-9.00) \mathrm{mmHg}(\mathrm{HSI})$ vs $0.00(-3.34-2.34) \mathrm{mmHg}(\mathrm{LSI})]$ was not significantly different between the two groups whereas diastolic blood pressure (DBP) rise in sustained handgrip [18.20 $\pm 3.49 \mathrm{mmHg}(\mathrm{HSI})$ vs $14.77 \pm 4.71 \mathrm{mmHg}(\mathrm{LSI})]$ was significantly higher in the HSI $(p=0.022)$. Conclusion: Cardiovascular sympathetic activity appears to increase in normotensive men with habitual high salt intake.

Key words: Cardiovascular autonomic function, Normotensive, Salt intake, Sympathetic activity, Parasympathetic activity
\end{abstract}

\section{Win Win Than', Ei Ei Khin², Mya Mya Thwin ${ }^{3, *}$}

'Department of Physiology, University of Medicine 2, Yangon, MYANMAR. ${ }^{2}$ Department of Physiology, University of Medicine 2, Yangon, MYANMAR. ${ }^{3}$ Physiology Unit, University Sultanzanial Abidin, Kuala Terengganu, Terengganu, MALAYSIA.

\section{${ }^{*}$ Correspondence}

\section{Dr. Mya MyaThwin}

Associate Professor, Physiology Unit, University Sultanzanial Abidin, Kuala Terengganu, Terengganu, MALAYSIA.

Phone: +6096275546

Email: drmyamyathwin2011@gmail. com

\section{History}

- Submission Date: 18-09-2019.

- Review completed: 04-11-2019;

- Accepted Date: 06-12-2019.

DOI : 10.5530/ijcep.2019.6.4.35

\section{Copyright}

(C) 2019 Phcog.Net. This is an openaccess article distributed under the terms of the Creative Commons Attribution 4.0 International license.

\section{INTRODUCTION}

Salt is a ubiquitous constituent of diets. ${ }^{[1]}$ Preference for salt increases the quantity of salt consumed and the incidence of hypertension is more in salt-preferring individuals than in no salt-preferring persons. ${ }^{[2]}$ Consumption of high dietary $\mathrm{Na}^{+}$may increase $\mathrm{BP}^{\left[{ }^{[3]}\right.}$ Hypertension is associated with increased sympathetic outflow. ${ }^{[4]}$ The major determinant of BP variability is sympathovagal balance of cardiovascular regulation. ${ }^{[5]}$ High dietary $\mathrm{Na}^{+}$can adversely affect the heart and areas of the brain that control autonomic outflow. ${ }^{[6]}$ The autonomic nervous system may play an important role in $\mathrm{Na}^{+}$-induced increases in $\mathrm{BP}^{[7]}$

$\mathrm{Pal}$ and colleagues reported that salt predilection is associated with sympathovagal imbalance in the form of sympathetic overactivity and vagal withdrawal in young Indian normotensives. ${ }^{[8]}$ However, Luft and associates discovered that sympathetic nervous system activity appears to decrease with salt loading in normal subjects. ${ }^{[9]} \mathrm{McNeely}$ and his co-workers found the increased vagal tone in normotensive persons on high salt intake. ${ }^{[10]}$ A meta-analysis of randomized controlled trials demonstrated that there was no change in sympathetic tone with long-term moderate $\mathrm{Na}^{+}$restriction in normotensives. ${ }^{[1]}$

Cite this article: Than WW, Khin EE, Thwin MM. Cardiovascular Autonomic Function in Normotensive Men with High Salt and Low Salt Intakes. Int J Clin Exp Physiol. 2019;6(4):134-8. 
DBP $<80 \mathrm{mmHg}$, serum creatinine $<1.5 \mathrm{mg} / \mathrm{dl}$ and fasting blood sugar (FBS) $<110 \mathrm{mg} / \mathrm{dl}$ were recruited from the office staff of the University of Medicine 2, Yangon and from surrounding areas. Exclusion criteria included: diabetes mellitus, cardiovascular diseases, neurological disorders, syncope, chronic alcoholics and smokers.

\section{Experimental Protocol}

Dietary sodium can be accessed by 24 -hr urine collection or a spontaneously voided morning urine sample. ${ }^{[12,13]}$ The spot urine sample reflects the 24-hr urinary $\mathrm{Na}^{+}$excretion. ${ }^{[14-17]}$ In Myanmar, ICNND (Interdepartmental Committee on Nutrition for National Defense) reported that average daily individual salt consumption is $11.8 \mathrm{~g}$ in Myanmar military in $1963 .^{[18]}$ Aye-Aye-Myint also found that mean daily salt intake was $11.08 \pm 0.62 \mathrm{~g}$ of sodium chloride in $1992 .{ }^{[19]}$ The estimation of salt consumption by Tanaka's formula was adequate when the consumption was between 9-12 g/day (Mill et al. 2015). ${ }^{[20]}$ Therefore, in our study, $24 \mathrm{hr}$ urinary $\mathrm{Na}^{+}$excretion was calculated from the spot urine sample by using the Tanaka's formula. ${ }^{[16]}$

\section{$24 \mathrm{~h} \mathrm{Na}$ excretion $(\mathrm{mEq} / \mathrm{d})=21.98 \times \mathrm{XNa}^{0.392}$}

$\mathrm{XNa}=\mathrm{Na}^{+}$concentration in the spot urine $(\mathrm{mEq} / \mathrm{L}) /$ creatinine concentration in the spot urine $(\mathrm{mg} / \mathrm{L}) \times$ predicted value of $24 \mathrm{hr}$ urinary $\mathrm{Cr}$ excretion $\left(\mathrm{PrU}_{\mathrm{Cr}} 24\right)$

$\operatorname{PrU}_{\mathrm{Cr}} 24(\mathrm{mg} / \mathrm{d})=-2.04$ Age (years) +14.89 Body weight $(\mathrm{kg})+16.14$ Height $(\mathrm{cm})-2244.45$ Human dietary $\mathrm{Na}^{+}$intake based on 24-hr urinary $\mathrm{Na}^{+}$excretion worldwide is usually between 114 and $210 \mathrm{mmol} /$ day. ${ }^{[21]}$ A meta-analysis based on 23 cohort studies and 2 randomized controlled trials investigated the incidence of cardiovascular disease events in populations exposed to dietary intakes of low sodium $(<115 \mathrm{mmol} /$ day $)$, usual sodium (low usual sodium: 115-165 mmol/day; high usual sodium: $166-215 \mathrm{mmol} /$ day) and high sodium ( $>215 \mathrm{mmol} /$ day). Both low and high sodium intakes are associated with increased incidence of cardiovascular disease compared with usual sodium intakes. ${ }^{[22]}$ Therefore, we defined the average $24 \mathrm{hr}$ urinary $\mathrm{Na}^{+}$excretion $166 \mathrm{mmol} /$ day or more as HSI and $<115 \mathrm{mmol} /$ day as LSI.

There is tremendous day-to-day variability in urinary sodium excretion and therefore to get the habitual dietary sodium, 4 early morning spot urine samples were collected. First and $2^{\text {nd }}$ samples were collected on Monday and Tuesday and two weeks later, $3^{\text {rd }}$ and $4^{\text {th }}$ samples were collected on Monday and Tuesday again. The average $24 \mathrm{hr}$ urinary $\mathrm{Na}^{+}$ excretion calculated from the 4 spot urine samples was used to identify the salt intake of the subject.

Among the recruited 106 men, 15 withdrew voluntarily from the study before completion of the collection of 4 urine samples according to their personal matters. Ninety one subjects completed the collection of 4 urine samples. Among the 91 subjects, 22 men for HSI and 19 men for LSI were obtained. The remaining participants were excluded from the study. To reduce the confounding effect of age and BMI on cardiovascular autonomic function, age and BMI-matched 17 HSI and 17 LSI subjects were selected to assess the cardiovascular autonomic function. The interval between the day of taking the last urine sample and the day of cardiovascular autonomic function assessment was in the range of 1 to 71 days.

On the day of cardiovascular autonomic function assessment, the subject was requested not to take drugs and caffeinated beverages and to refrain from heavy exercise. The tests were performed at least $2 \mathrm{hr}$ after last meal. The examination room was kept quiet with temperature $22-25^{\circ} \mathrm{C}$. After instrumentation, the subject was resting on a chair for $15 \mathrm{~min}$. Baseline HR was calculated from the average of 10 consecutive RR intervals of ECG. BP was measured 3 times at one-minute interval and the average was taken as the baseline. Valsalva maneuver, deep breathing, orthostasis and sustained handgrip (SHG) were then carried out in series resting 10 to 15 min between each test until the HR returned to the baseline. ${ }^{[23]}$

\section{Measurements}

BMI was measured with a bathroom scale and a flexible inch tape. FBS was measured by Glucometer (Prodigy Preferred Blood Glucose Meter, Prodigy Diabetes Care, Taiwan). Serum and urine creatinine were determined by Humalyzer Primus (Human, Germany) and auto creatinine liquicolor (Human, Germany). $\mathrm{Na}^{+}$concentration of urine was measured by the use of graphite furnace atomic absorption spectrometer (GBC 932plus, Serial number A4982, GBC Scientific Equipment Pty. Ltd., Austratlia). HR was recorded in lead II ECG and analysis was done by computerized ECG system (containing PowerLab 8/35 - 8 Channels (PL3508) data acquisition system with FE132 BioAmp and LabChart software, AD Instruments, Australia). BP was measured with mercury sphygmomanometer (Kenxin, Hong Kong) and stethoscope (3M Littmann, classic II S.E, USA). Handgrip dynamometer (CH. Stoelting, USA) was used for the SHG.

\section{HR Response and Valsalva Maneuver}

The subject blew into a disposable mouthpiece (a $5 \mathrm{cc}$ disposable syringe) connected to a modified sphygmomanometer holding at a pressure of $40 \mathrm{mmHg}$ for $15 \mathrm{sec}$ while ECG was recording continuously. The maneuver was performed 3 times with one-minute interval in between. The ratio of the longest RR interval after the maneuver (reflecting overshoot bradycardia following release) to the shortest RR interval during the maneuver (reflecting the tachycardia during strain) was taken as VR. ${ }^{[23]}$ The mean of 3 VRs was taken as the final value.

\section{HR Variation and Deep Breathing}

The subject was sitting quietly and breathing deeply at six breaths per minute. The minimum and maximum HR during the breathing cycle was measured. The result (DBD) was expressed as the mean of the differences between maximum and minimum HR for 6 breathing cycles.

\section{HR Response and Standing}

After lying quietly on a couch for $15 \mathrm{~min}$, the subject stood up unaided within $5 \mathrm{sec}$ and remained motionless for two minutes. To get the shortest $\mathrm{RR}$ interval around $15^{\text {th }}$ beat and the longest $\mathrm{RR}$ interval around $30^{\text {th }}$ beat after standing up, the RR interval of 5 heart beats before and after the $15^{\text {th }}$ beat (i.e. from $10^{\text {th }}$ to $20^{\text {th }}$ beats) and the $30^{\text {th }}$ beat (i.e. from $25^{\text {th }}$ to $35^{\text {th }}$ heart beats) were measured. The HR response, 30:15 ratio, was expressed by the ratio of the longest $R R$ interval around $30^{\text {th }}$ beat to the shortest $R R$ interval around $15^{\text {th }}$ beat.

\section{SBP Response and Standing}

After lying quietly on a couch for 15 min, BP was measured 3 times with one-minute interval and the average was taken as lying BP. Then the subject stood up unaided (within $5 \mathrm{sec}$ ) and remained motionless for $2 \mathrm{~min}$. BP was measured at one minute after standing up. The difference in SBP one minute after standing up and that in lying position was taken as postural change in BP. The Consensus Committee of the American Autonomic Society and the American Academy of Neurology defines that orthostatic hypotension is reduction of SBP of at least $20 \mathrm{mmHg}$ or DBP of at least $10 \mathrm{mmHg}$, within 1-3 min. ${ }^{[24]}$ Therefore, BP was assessed at one minute after standing.

\section{DBP Response and SHG}

The participants were sitting down during the handgrip trial. In handgrip dynamometer, one dial hand "freezes" at the maximum grip achieved, while the other follows the grip up or down to show the current squeeze 
strength. Handgrip was maintained at the workload of 30 percent of maximum voluntary contraction for $5 \mathrm{~min}$ by using handgrip dynamometer with dominant hand. To verify the workload throughout $5 \mathrm{~min}$, the dial hand that freezes at the maximum grip achieved was set at $30 \%$ of maximal voluntary contraction while the target workload was monitored by the other dial hand. BP was measured 3 times just before and at one-minute interval during handgrip. The difference between the highest DBP during handgrip and the mean of the 3 DBP readings just before handgrip was taken as the response.

\section{Statistical Analysis of Data}

Statistical analysis was done with SPSS software, version 22 (IBM Corporation, New York, United States). Mean \pm SD was used to present normally distributed data and comparison was done by independent $t$ test. Skewed data were expressed as median and interquartile range and compared by Mann-Whitney $\mathrm{U}$ test. Statistical significance was set as $p$ values of less than 0.05 .

\section{RESULTS}

\section{General Characteristics}

BMI, serum creatinine, FBS, resting HR, resting SBP, DBP and MAP were not significantly different. Average $24-\mathrm{hr}$ urinary $\mathrm{Na}^{+}$excretion was significantly different $(p<0.001)$ (Table 1$)$.

\section{HR Response and Valsalva Maneuver}

In HSI group, the mean longest RR interval was $1.02 \pm 0.20 \mathrm{sec}$ and mean shortest RR interval was $0.63 \pm 0.11 \mathrm{sec}$. In LSI group, the mean longest $R R$ interval was $0.99 \pm 0.16 \mathrm{sec}$ and the mean shortest $\mathrm{RR}$ interval was $0.58 \pm 0.11 \mathrm{sec}$. Mean VRs were $1.64 \pm 0.36$ (HSI) and $1.78 \pm 0.49$ (LSI) and were not significantly different ( $p=0.355$, independent $t$ test).

\section{HR Variation and Deep Breathing}

In the HSI group, maximum HR was $89.57 \pm 12.87$ beats/min and minimum HR was $65.05 \pm 12.32$ beats/min. In the LSI group, maximum HR was $93.38 \pm 6.70$ beats/min and minimum HR was $70.46 \pm 8.79$ beats/ min. Deep breathing differences were $24.51 \pm 9.56$ beats $/ \mathrm{min}$ (HSI) and $22.93 \pm 6.37$ beats/min (LSI) and not statistically significant $(p=0.574$, independent $t$ test).

\section{HR Response and Standing}

Mean HRs during lying in subjects were $66.23 \pm 11.97$ beats/min (HSI) and $68.82 \pm 9.47$ beats/min (LSI). In the HSI group, mean HRs were $101.63 \pm 12.01$ beats/min around $15^{\text {th }}$ beat and $79.02 \pm 15.97$ beats $/ \mathrm{min}$ around $30^{\text {th }}$ beat on standing.

In the LSI group, the mean HR was $103.45 \pm 9.75$ beats/min around $15^{\text {th }}$ beat and $80.80 \pm 14.61$ beats/min around $30^{\text {th }}$ beat. In HSI group, the median (IQR) of the longest RR interval around $30^{\text {th }}$ beat during standing was $0.82(0.69-0.91) \mathrm{sec}$ and that of the shortest RR interval around $15^{\text {th }}$ beat during standing was $0.60(0.53-0.65)$ sec. In LSI group, the longest $\mathrm{RR}$ interval around $30^{\text {th }}$ beat was $0.73(0.63-0.87) \mathrm{sec}$ and the shortest RR interval around $15^{\text {th }}$ beat was $0.60(0.53-0.62) \mathrm{sec}$. The $30: 15$ ratios [median (IQR)] were 1.34 (1.12-1.46) (HSI) and 1.19 (1.13-1.52) (LSI) and not significantly different $(p=0.756$, Mann-Whitney $U$ test).

\section{SBP Response and Standing}

In HSI group, SBP during lying was $109.84 \pm 11.02 \mathrm{mmHg}$ and mean SBP at one minute after standing was $111.88 \pm 13.86 \mathrm{mmHg}$. In the LSI group, mean SBP during lying was $109.02 \pm 7.58 \mathrm{mmHg}$ and mean SBP at one minute after standing was $108.94 \pm 8.84 \mathrm{mmHg}$. SBP changes in response to standing were less than $10 \mathrm{mmHg}$. The changes in SBP at one minute after standing [median (IQR)] were $-0.67(-4.00-9.00) \mathrm{mmHg}$
(HSI) and $0.00(-3.34-2.34) \mathrm{mmHg}$ (LSI) and not significantly different ( $p=0.593$, Mann-Whitney U test).

\section{BP Response to Sustained Handgrip}

In HSI group, the mean SBP before SHG was $103.61 \pm 10.80 \mathrm{mmHg}$ and the mean highest SBP during SHG was $118.59 \pm 14.21 \mathrm{mmHg}$. In LSI group, the mean SBP before SHG was $104.00 \pm 8.80 \mathrm{mmHg}$ and the mean highest SBP during SHG was $116.94 \pm 9.06 \mathrm{mmHg}$. The mean changes in SBP were $14.98 \pm 5.55 \mathrm{mmHg}$ (HSI) and $12.94 \pm 6.53 \mathrm{mmHg}$ (LSI). Increase in SBP was higher in HSI group than in LSI group but not statistically significant ( $p=0.334$, independent $t$ test).

All 34 participants completed the $5 \mathrm{~min}$ of handgrip exercise. In HSI group, the mean DBP before SHG was $68.75 \pm 8.29 \mathrm{mmHg}$ and the mean highest DBP during SHG was $86.94 \pm 10.05 \mathrm{mmHg}$. In LSI group, the mean DBP before SHG was $72.06 \pm 7.44 \mathrm{mmHg}$ and the mean highest DBP during SHG was $86.82 \pm 9.06 \mathrm{mmHg}$. The mean changes in DBP were $18.20 \pm 3.49 \mathrm{mmHg}$ (HSI) and $14.77 \pm 4.71 \mathrm{mmHg}$ (LSI). Increase in DBP was significantly higher $(p=0.022)$ in HSI group (Table 2).

\section{DISCUSSION}

In 1982, a battery of autonomic function tests, heart rate responses to Valsalva manoeuvre, deep breathing and standing (tests of parasympathetic function) and BP responses to standing and sustained handgrip (tests of sympathetic function), are devised by Ewing and Clarke. ${ }^{[23]}$ The American Academy of Neurology has recommended this battery of tests as the standard tests for assessment of autonomic dysfunction. ${ }^{[2]}$ In the INTERSALT study in the late 1980 's, $\mathrm{Na}^{+}$intake higher by $100 \mathrm{mmol} /$ day

\section{Table 1: General characteristics.}

\begin{tabular}{|cccc|}
\hline Parameters & HSI $(\boldsymbol{n}=17)$ & LSI $(\boldsymbol{n}=17)$ & $\boldsymbol{p}$ value \\
Age (years) & $25.24 \pm 6.05$ & $25.94 \pm 6.30$ & 0.741 \\
BMI $\left(\mathrm{kg} / \mathrm{m}^{2}\right)$ & $20.58 \pm 2.02$ & $20.32 \pm 1.66$ & 0.687 \\
Serum creatinine $(\mathrm{mg} / \mathrm{dl})$ & $0.99 \pm 0.18$ & $1.01 \pm 0.13$ & 0.666 \\
FBS $(\mathrm{mg} / \mathrm{dl})$ & $92.76 \pm 7.35$ & $94.71 \pm 8.85$ & 0.492 \\
Resting HR (beats/min) & $80.02 \pm 11.60$ & $83.16 \pm 8.36$ & 0.373 \\
Resting SBP (mmHg) & $105.84 \pm 9.63$ & $106.31 \pm 6.50$ & 0.868 \\
Resting DBP (mmHg) & $67.96 \pm 9.49$ & $69.49 \pm 7.77$ & 0.610 \\
Resting MAP (mmHg) & $81.95 \pm 9.37$ & $81.76 \pm 6.08$ & 0.947 \\
Average 24-hr urinary sodium & $174.53 \pm 8.71$ & $108.83 \pm 7.89$ & $<0.001$ \\
excretion (mmol/day) & & & \\
\hline
\end{tabular}

Data in the table are expressed as mean \pm standard deviation. Statistical differences were tested using independent $t$ - test. Significance $p \leq 0.05$. HSI $=$ high salt intake, LSI = low salt intake, BMI = body mass index, FBS = fasting blood sugar, $\mathrm{HR}=$ heart rate, $\mathrm{SBP}=$ systolic blood pressure, $\mathrm{DBP}=$ diastolic blood pressure, $\mathrm{MAP}=$ mean arterial pressure.

Table 2: Mean DBP response to sustained handgrip.

\begin{tabular}{|c|c|c|c|}
\hline Parameters & $\begin{array}{c}\text { High salt } \\
\text { intake } \\
\text { (mean } \pm \text { SD) } \\
(n=17)\end{array}$ & $\begin{array}{c}\text { Low salt } \\
\text { intake } \\
\text { (mean } \pm \text { SD) } \\
(n=17)\end{array}$ & $p$ value \\
\hline DBP before SHG (mmHg) & $68.75 \pm 8.29$ & $72.06 \pm 7.44$ & 0.229 \\
\hline $\begin{array}{l}\text { Highest DBP during SHG } \\
\qquad(\mathrm{mmHg})\end{array}$ & $86.94 \pm 10.05$ & $86.82 \pm 9.06$ & 0.927 \\
\hline $\begin{array}{c}\text { Change in DBP to SHG } \\
(\mathrm{mmHg})\end{array}$ & $18.20 \pm 3.49$ & $14.77 \pm 4.71$ & $0.022^{*}$ \\
\hline
\end{tabular}

*indicates significant difference between high salt intake group and low salt intake group $(p<0.05)$. Compared by independent $t$ - test. 
increased SBP by only $\sim 3$ to $6 \mathrm{mmHg}$ and $\mathrm{DBP}$ by only 0 to $3 \mathrm{mmHg} .{ }^{[25]}$ In our study, the mean $\mathrm{Na}^{+}$intake of the HSI group, (174.53 $\pm 8.71 \mathrm{mmol} /$ day) and that of the low salt intake group $(108.83 \pm 7.89 \mathrm{mmol} /$ day $)$ differ only $\sim 65.7 \mathrm{mmol} /$ day. The results of 3 parameters (Valsalva ratio, DBD and 30:15 ratio) which reflects the cardiac parasympathetic function were not significantly different between the HSI group and the LSI group in the present study. HR variation during deep breathing reflected cardiac parasympathetic activity. ${ }^{[23]}$ The $30: 15$ ratio, commonly used to check the parasympathetic function, had been recommended as an index of cardiovagal function. ${ }^{[26]}$ The approximation of salt intake of the subjects in the present study was $108.83-174.53 \mathrm{mmol} /$ day of sodium with the usual range of human dietary $\mathrm{Na}^{+}$intake (114 and $210 \mathrm{mmol} /$ day $)^{[21]}$ and it might be the basis for no different findings of cardiac parasympathetic function between the two groups.

Cardiac parasympathetic activity was decreased in hypertensive patients when compared with normotensive subjects. ${ }^{[27]}$ Baroreceptor reflex may involve in the regulation of the HR response to Valsalva maneuver ${ }^{[28]}$ and standing. ${ }^{[29]}$ Baroreflex sensitivity has a negative correlation with age. ${ }^{[28,30]}$ In this regard, the age-related decrease in baroreflex sensitivity may take part some role in decreased cardiac parasympathetic function with aging. Rossi and colleagues found that parasympathetic function tests decreased significantly in obese subjects than in the non-obese subjects. ${ }^{[31]}$ The participants in our study were 20 to 40 years aged normotensives and with normal BMI.

In normotensives, to maintain BP, the heart and peripheral vessels seem to accommodate to the changes in plasma volume that follow changes in $\mathrm{Na}^{+}$consumption. ${ }^{[8]}$ When $\mathrm{Na}^{+}$intake is high, there will be increase in extracellular fluid volume, increase in blood volume, increase in wall stretch in the heart and blood vessels, increase in the discharge rate of baroreceptors and the resultant decrease in cardiac activity and vascular tone. There will be the reverse mechanism when the $\mathrm{Na}^{+}$intake is low. ${ }^{[32,33]}$ The cardiac parasympathetic function of the HSI group was not different from that of the LSI group in the present study. It might be due to the fact that the participants in both groups of the present study were healthy normotensive men and hence their baroreflex activity might be adequate to accommodate the effect of $\mathrm{Na}^{+}$consumption on plasma volume.

Postural hypotension (fall in SBP more than $20 \mathrm{mmHg}$ between lying and one minute of standing) was found in none of the subjects in our study and therefore the subjects might be free from sympathetic insufficiency. The SBP changes between lying and standing in the HSI group was not significantly different from that of the LSI group. Therefore, the effect of SI in the range of $108.83-174.53 \mathrm{mmol} /$ day of $\mathrm{Na}^{+}$might not be related to SBP changes from lying to standing in the present study.

In this study, the mean SBP and DBP rose in both groups during sustained handgrip. Sustained muscle contraction caused a rise in SBP and DBP and HR. The stimulus derived from exercising muscle and central command. During a voluntary muscle contraction, a release from vagal tone initiates an increase in HR and the rise in arterial pressure could be ascribed both to HR acceleration and to an effect on systemic vascular resistance mediated by the sympathetic nervous system. ${ }^{[34]} \mathrm{Pal}$ and colleagues concluded that an increase in DBP during sustained handgrip in the salt-preferring group indicated increased sympathetic reactivity in salt-preferring subjects, as the rise in DBP during sustained handgrip reflected the state of sympathetic reactivity. ${ }^{[35]}$ Previous discoveries pointed out the effect of HSI on sympathetic activity. ${ }^{[7,36]}$ In healthy individuals, urinary excretion is the primary mechanism for maintaining $\mathrm{Na}^{+}$balance. ${ }^{[37]}$ Normally about, $99 \%$ of the filtered $\mathrm{Na}^{+}$was reabsorbed by the kidney ${ }^{[38]}$ High salt diet might increase plasma and cerebrospinal fluid $\mathrm{Na}^{+}$concentration.

Elevated plasma or cerebrospinal fluid $\mathrm{Na}^{+}$concentration contributes to elevated sympathetic nerve activity and arterial BP in animals and humans. ${ }^{[39-42]}$ Both in vivo and in vitro electrophysiological studies have reported that the organum vasculosum of the lamina terminalis and the subfornical organ contained neurons that were intrinsically osmosensitive. ${ }^{[43,44]}$

Hypothalamic paraventricular neurons influenced sympathetic nerve activity and arterial BP through mono- and polysynaptic pathways to several sympathetic brain regions such as the rostral ventrolateral medulla (RVLM) and spinal intermediolateral cell column cord. ${ }^{[45,46]}$ Elevated dietary $\mathrm{Na}^{+}$may sensitize sympathetic neurons in the RVLM, ${ }^{[47-49]}$ causing a greater sympathetic response to a variety of stimuli, ${ }^{[50]}$ including skeletal muscle contraction. ${ }^{[1]}$ This increased responsiveness might be associated with a higher DBP response to sustained handgrip in normotensive men with HSI in the present study.

Campese and associates evaluated and reported that plasma norepinephrine level was significantly higher in the hypertensives than normotensives during high $\mathrm{Na}^{+}$intake. They suggested that there was hyperactivity of the sympathetic nervous system in these patients. ${ }^{[52]} \mathrm{Pal}$ and coworkers assessed the link of salt preference to sympathovagal imbalance measured by $\mathrm{HR}$ variability analysis in healthy prehypertensive subjects and they found that salt preference is associated with sympathovagal imbalance caused by sympathetic overactivity and vagal withdrawal. ${ }^{\left[{ }^{[8}\right.}$ These studies indicated that HSI may cause sympathovagal imbalance and sympathetic hyperactivity which would lead to prehypertension and hypertension. According to our study, even in normotensive men, high salt intake may lead to greater cardiovascular sympathetic reactivity than low salt intake.

\section{Limitations of the Study}

Concerning limitations of present study, the cross-sectional design obstructs the establishment of causality between SI and cardiovascular autonomic function. Salt sensitivity and resistance of the participants was not assessed. Serum $\mathrm{Na}^{+}$level of the participants were not determined. There are limitations to using a spot urine sample to assess 24-hr urinary sodium excretion but this weakness is partially offset by performing a spot urine collection on 4 separate days. It has been well known that there is increase in salt sensitivity with aging. Our subjects were young in both groups and it is possible that the redundant mechanisms that control the cardiovascular system are able to tolerate wider ranges of sodium intake in young adults than older adults. This may be the reasons that the VR, DBD, 30:15 ratio and SBP change from lying to standing were not significantly different between the two groups. The blood pressure response to handgrip exercise is an indirect index of sympathetic responses.

\section{CONCLUSION}

Regarding two tests of sympathetic function, although the SBP response to standing was not significantly different, the DBP response to sustained handgrip was significantly higher in the high salt intake group. High salt intake might increase cardiovascular sympathetic reactivity even in normotensive men. Future studies need to confirm an association between the degree of salt consumption and cardiovascular autonomic function and underlying mechanisms.

\section{ACKNOWLEDGEMENT}

The authors acknowledge the University of Medicine 2, Yangon for supporting the PowerLab 8/35 - 8 Channels (PL3508) data acquisition system with FE132 BioAmp and LabChart software, ADInstruments, Australia, staff from the Common Research Laboratory of the University of Medicine 2, Yangon for helping in performing the biochemical analysis and the participants for generously denoting the time.

\section{CONFLICT OF INTEREST}

The authors declare no conflict of interest. 
Than, et al.: Salt intake and autonomic function

\section{ABBREVIATIONS}

HR: Heart rate; BP: Blood pressure; SBP: Systolic blood pressure; DBP: Diastolic blood pressure; BMI: Body mass index; FBS: Fasting blood sugar; ECG: Electrocardiogram; $\mathbf{N a}^{+}$: Sodium; HSI: High salt intake; LSI: Low salt intake; VR: Valsalva ratio; DBD: Deep breathing difference; SHG: Sustained handgrip.

\section{REFERENCES}

1. Beauchamp GK, Engelman K. High salt intake. Sensory and behavioral factors. Hypertension. 1991;17(1_supplement):1176.

2. Hori Y, Toyoshima H, Kondo T, Tamakoshi K, Yatsuya H, Zhu S, et al. Gender and age differences in lifestyle factors related to hypertension in middle-aged civil service employees. J Epidemiol. 2003;13(1):38-47.

3. Weinberger MH. Sodium and blood pressure 2003. Curr Opinion Cardiol. 2004; 19(4):353-6.

4. Anderson EA, Sinkey CA, Lawton WJ, Mark AL. Elevated sympathetic nerve activity in borderline hypertensive humans. Evidence from direct intraneural recordings. Hypertension. 1989;14(2):177-83.

5. Laitinen T, Hartikainen J, Niskanen L, Geelen G, Länsimies E. Sympathovagal balance is major determinant of short-term blood pressure variability in healthy subjects. Am J Physiol. 1999;276(4):H1245-52

6. Kotchen TA, Cowley JAW, Frohlich ED. Salt in health and disease-a delicate balance. N Engl J Med. 2013;368(13):1229-37.

7. Farquhar WB, Edwards DG, Jurkovitz CT, Weintraub WS. Dietary sodium and health: More than just blood pressure. J Am Coll Cardiol. 2015;65(10):1042-50.

8. Pal GK, Adithan C, Dutta TK, Pal P, Nanda N, Kiran AS, et al. Preference for salt contributes to sympathovagal imbalance in the genesis of prehypertension. Europ J Clin Nutr. 2013;67(6):586.

9. Luft FC, Rankin LI, Henry DP, Bloch Richard, Grim CE, Weyman AE, et al. Plasma and urinary norepinephrine values at extremes of sodium intake in normal man. Hypertension. 1979;1(3):261-6

10. McNeely JD, Windham BG, Anderson DE. Dietary sodium effects on heart rate variability in salt sensitivity of blood pressure. Psychophysiology. 2008:45(3):405-11

11. He FJ, MacGregor GA. Effect of modest salt reduction on blood pressure: $A$ meta-analysis of randomized trials. Implications for public health. J Hum Hypertens. 2002;16(11):761.

12. Kawasaki T, Itoh K, Uezono K, Sasaki H. A simple method for estimating $24 \mathrm{hr}$ urinary sodium and potassium excretion from second morning voiding urine specimen in adults. Clin Exper Pharmacol Physiol. 1993;20(1):7-14.

13. Mann MC, Exner DV, Hemmelgarn BR, Turin TC, Sola DY, Ahmed SB. Impact of gender on the cardiac autonomic response to angiotensin II in healthy humans. J Appl Physiol. 2012;112(6):1001-7.

14. Walker WG, Whelton PK, Saito HI, Russell RP, Hermann JU. Relation between blood pressure and renin, renin substrate, angiotensin II, aldosterone and urinary sodium and potassium in 574 ambulatory subjects. Hypertension. 1979; 1(3):287-91.

15. Elliott P, Dyer A, Kesteloot H, Freeman J, Shipley M, Stamler R, et al. Sodium/ creatinine and sodium/potassium ratio in spot urines are positively related to blood pressure: The INTERSALT study. J Hypertens. 1992;10:141.

16. Tanaka T, Okamura T, Miura $K$, Kadowaki $T$, Ueshima $H$, Nakagawa $H$, et al. A simple method to estimate populational 24-hr urinary and potassium excretion using a casual urine specimen. J Hypertens. 2002;16(2):97-103.

17. Khaw KT, Bingham S, Welch $A$, Luben R, O'Brien $E$, Wareham N, et al. Blood pressure and urinary sodium in men and women: The Norfolk Cohort of the European Prospective Investigation into Cancer (EPIC-Norfolk). Am J Clin Nutr. 2004;80(5):1397-403.

18. ICNND. A report by the Interdepartmental Committee on Nutrition for National Defence, Union of Burma. 1963

19. Aye-Aye-Myint. Mineral elements composition of snacks, daily mineral intake and serum mineral level of Myanmar adults. University of Medicine, Mandalay. M Med Sc Thesis. 1992

20. Mill JG, Rodrigues SL, Baldo MP, Malta DC, Szwarcwald CL. Validation study of the Tanaka and Kawasaki equations to estimate the daily sodium excretion by a spot urine sample. Rev Bras Epidemiol. 2015;18:224-37.

21. McCarron DA, Kazaks AG, Geerling JC, Stern JS, Graudal NA. Normal range of human dietary sodium intake: A perspective based on 24-hr urinary sodium excretion worldwide. Am J Hypertens. 2013;26(10):1218-23.

22. Graudal N, Jürgens G, Baslund B, Alderman MH. Compared with usual sodium intake, low-and excessive-sodium diets are associated with increased mortality: A meta-analysis. Am J Hypertens. 2014;27(9):1129-37.

23. Ewing DJ, Clarke BF. Diagnosis and management of diabetic autonomic neuropathy. BMJ. 1982;285(6346):916.
24. American Academy of Neurology. Assessment of clinical autonomic testing report of Therapeutics and Technology Assessment subcommittee of American Academy of Neurology. Neurology. 1996:46:873-80.

25. Stamler J. The INTERSALT Study: Background, methods, findings and implications. Am J Clin Nutr. 1997;65(2):626S-42S.

26. Low PA, Sletten DM. Textbook of Clinical Autonomic Disorders. $3^{\text {rd }}$ ed. Baltimore and Philadelphia: Lippincott Williams and Wilkins. 2008.

27. Kumar-Endukuru C, DeepthiTS, Singh SB. Study of Autonomic Function Tests in Hypertensives. Int J Li Sci Res. 2014;2(4):43-7.

28. Shimada K, Kitazumi T, Sadakane N, Ogura H, Ozawa T. Age-related changes of baroreflex function, plasma norepinephrine and blood pressure. Hypertension. 1985;7(1):113-7.

29. Borst C, Wieling W, Brederode JFV, Hond A, DeRijk LG, Dunning AJ. Mechanisms of initial heart rate response to postural change. Am J Physiol. 1982;243(5):H676-81.

30. Gerritsen J, TenVoorde BJ, Dekker JM, Kostense PJ, Bouter LM, Heethaar RM Baroreflex sensitivity in the elderly: Influence of age, breathing and spectral methods. Clin Sci. 2000;99(5):371-81.

31. Rossi M, Marti G, Ricordi L, Fornasari G, Finardi G, Fratino P, et al. Cardiac autonomic dysfunction in obese subjects. Clin Sci. 1989;76(6):567-72.

32. Borst JGG, Borst-de Geus A. Hypertension explained by Starling's theory of circulatory homoeostasis. The Lancet. 1963;281(7283):677-82.

33. Meneton $P$, Jeunemaitre $X$, DeWardener HE, Macgregor GA. Links between dietary salt intake, renal salt handling, blood pressure and cardiovascular diseases. Physiol Rev. 2005;85(2):679-715.

34. Freyschuss UL. Elicitation of heart rate and blood pressure increase on muscle contraction. J Applied Physiol. 1970;28(6):758-61.

35. Pal GK, Chandrasekaran A, Pal P, Nivedita N, Indumathy J, Sirisha A. Prehypertension status, cardiometabolic risks and decreased baroreflex sensitivity are linked to sympathovagal imbalance in salt-preferring individuals. Clin Exper Hypertens. 2015;37(8):609-15.

36. Stocker SD, Monahan KD, Browning KN. Neurogenic and sympathoexcitatory actions of $\mathrm{NaCl}$ in hypertension. Curr Hypertens Rep. 2013;15(6):538-46.

37. Holbrook JT, Patterson KY, Bodner JE, Douglas LW, Veillon C, Kelsay JL, et al. Sodium and potassium intake and balance in adults consuming self-selected diets. Am J Clin Nutr. 1984;40(4):786-93.

38. Barrett KE, Barman SM, Boitano S, Brooks H. Ganong's review of medical physiology. 23 ${ }^{\text {rd }}$ Ed. NY: McGraw-Hill Medical. 2009

39. Nakamura K, Cowley JAW. Sequential changes of cerebrospinal fluid sodium during the development of hypertension in Dahl rats. Hypertension. 1989;13(3):243-9

40. Huang BS, Vliet BNV, Leenen FH. Increases in CSF [Na+] precede the increases in blood pressure in Dahl $\mathrm{S}$ rats and SHR on a high-salt diet. Am J Physiol. 2004;287(3):H1160-6.

41. O'Donaughy TL, Qi Y, Brooks VL. Central action of increased osmolality to support blood pressure in deoxycorticosterone acetate-salt rats. Hypertension. 2006;48(4):658-63.

42. Schmidlin O, Forman A, Sebastian A, Morris JRC. Sodium-selective salt sensitivity: Its occurrence in blacks. Hypertension. 2007;50(6):1085-92.

43. Bourque CW. Central mechanisms of osmosensation and systemic osmoregulation. Nat Rev Neurosci. 2008;9(7):519

44. Ciura S, Liedtke W, Bourque CW. Hypertonicity sensing in organum vasculosum lamina terminalis neurons: A mechanical process involving TRPV1 but not TRPV4. J Neurosci. 201;31(41):14669-76.

45. Antunes VR, Yao ST, Pickering AE, Murphy D, Paton JF. A spinal vasopressinergic mechanism mediates hyperosmolality-induced sympathoexcitation. J Physiol. 2006;576(2):569-83.

46. Stocker SD, Osborn JL, Carmichael SP. Forebrain osmotic regulation of the sympathetic nervous system. Clin Exper Pharmacol Physiol. 2008;35(5-6):695-700.

47. Pawloski-Dahm CM, Gordon FJ. Increased dietary salt sensitizes vasomotor neurons of the rostral ventrolateral medulla. Hypertension. 1993;22(6):929-33.

48. Ito S, Gordon FJ, Sved AF. Dietary salt intake alters cardiovascular responses evoked from the rostral ventrolateral medulla. Am J Physiol. 1999;276(6):R1600-7.

49. Adams JM, Bardgett ME, Stocker SD. Ventral lamina terminalis mediates enhanced cardiovascular responses of rostral ventrolateral medulla neurons during increased dietary salt. Hypertension. 2009;54(2):308-14.

50. Stocker SD, Madden CJ, Sved AF. Excess dietary salt intake alters the excitability of central sympathetic networks. Physiol Behav. 2010;100(5):519-24.

51. Yamauchi K, Tsuchimochi H, Stone AJ, Stocker SD, Kaufman MP. Increased dietary salt intake enhances the exercise pressor reflex. Am J Physiol. 2013;306(3):H450-4

52. Campese VM, Romoff MS, Levitan D, Saglikes Y, Friedler RM, Massry SG. Abnormal relationship between sodium intake and sympathetic nervous system activity in salt-sensitive patients with essential hypertension. Kidney Int. 1982;21(2):371-8. 